\title{
Transplant Waiting List
}

National Cancer Institute

\section{Source}

National Cancer Institute. Transplant Waiting List. NCI Thesaurus. Code C100078.

A registry of patients awaiting an organ transplant. (ACC) 